\title{
Optimizing roughness and residual stresses through controlled shot peening and isotropic finishing of surfaces
}

\author{
A. Zanini \\ Curtiss Wright Surface Technologies, Metal Improvement Co, \\ Piacenza, Italy
}

\begin{abstract}
Controlled shot peening and the related beneficial compressive residual stresses has long been a powerful weapon in the engineering designer's armory in combating fatigue, stress corrosion, fretting and wear. As requirements for improved performance increase, surface engineering is becoming more important and the benefits of controlled shot peening are being incorporated into the design of components. In conjunction with controlled shot peening, isotropic finishing gives further life improvement to the already highly stressed parts. isotropic Finishing has been developing as a post shot peening treatment in situations where metal to metal contact occurs, and low friction is required: the combination of beneficial residual stress and roughness control are essential on modern applications to extend life and improve performance. It is not necessary to remove all of the witness of shot peening, but a percentage resulting in a matrix of load bearing smooth areas interspersed with valleys for oil pockets, reducing Ra values and providing a negative Rsk.
\end{abstract}

Keywords: shot peening, isotropic finishing, superfinishing, residual stress, roughness, microhoning.

\section{Introduction}

The failure of high performance and critical components most commonly occurs through processes of fatigue and is often caused by a combination of different mechanism. For this reason, residual stress in the material and surface roughness must be analyzed together to give then best results. Controlled shot peening and treatments linked to it can control and modify in accurate and repeatable ways 
both of these aspects. Surface condition was not a critical feature to engineers many years ago. Shot peening was considered to be a'black art' of sometimes inconsistent benefit. This was partly due to ignorance of the shot peening process and partly a lack of understanding of surfaces, manufacturing techniques and their influence. In the last 20 years, roughness and stresses have been better understood and as shot peening has developed from its shot blasting roots, the $\mathrm{s}$ progression has become better appreciated in a great array of application. Today controlled shot peening is an accepted process where inducement of compressive residual stresses is the main target. In addition to bending and contact fatigue, many failure mechanisms (e.g. SCC, fretting, intergranular corrosion, galling, wear) can be postponed or avoided altogether with the application of controlled shot peening, laser peening and isotropic finishing.

\section{Controlled shot peening and isotropic finishing}

To achieve the optimum surface condition, both shot peening and superfinishing need to be conducted. However, it is feasible to split the processes to face different mechanism. The following is an explanation of each with details of how each affect the substrate.

\subsection{Controlled shot peening}

Controlled shot peening is the cold working of a surface with particles, impinging at predetermined velocity under controlled conditions. The surface yields but it is restrained by the substrate with the result that a residual compressive stress is induced as shown in Figure 1 [1].
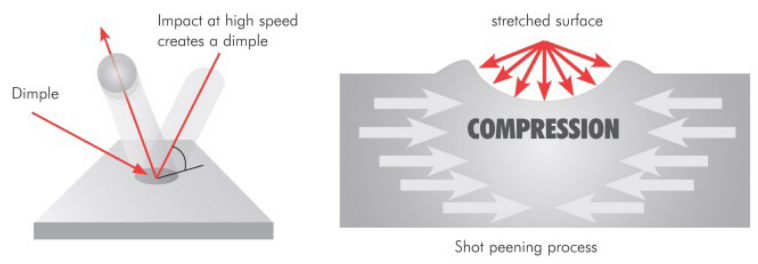

Figure 1: $\quad$ Shot peening dimple and residual compression stress generation.

The profile of the stress has been assessed and is generation from a twofold mechanism [2]. The first, a plastic stretching of the surface due to tangential forces generated by multiple shot indentation, and second a subsurface stress linked to the Hertzian pressure created by forces normal to the surface due to shot impingement. The magnitude of the compressive stress is directly related to the base materials yield strength and is approximately equal to $80 \%$ of that value in compression. 


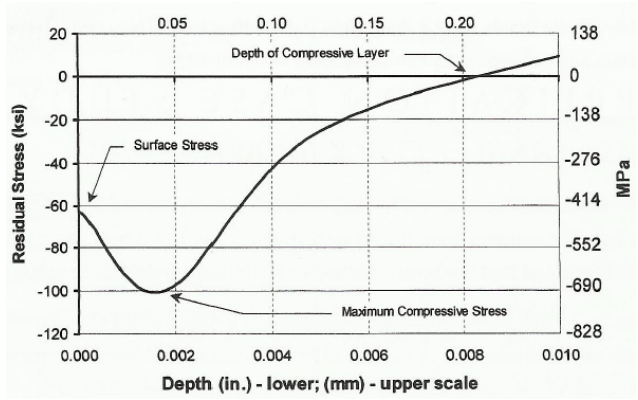

Figure 2: $\quad$ Typical shot peening residual stress profile.

Concern has been expressed that shot peening is only applicable to soft materials, but in practice the greatest benefit is noted on hard materials. Steel above 45 Rccan exhibit notch sensitivity to a level that fatigue strength begins to diminish over this level. However, carburized and nitrided steels will undergo localized yielding during the action of shot peening, in the near surface area [3].

Different media are used and these include cast and cut wire steel or stainless steel shot, glass and ceramic beads in size ranges from 50 to 3000 micron. Media selection will depend on the geometry of the part, the material and its strain hardening rate, the application (fatigue, stress corrosion cracking, galling, fretting) and in service conditions. However, in addition to inducing a residual compressive stress, several other changes occur. It is a cold working process therefore an increase in hardness will result, a change in magnitude and type of surface roughness, grain refinement and changes in martensite/austenite levels. These modifications to the surface have a number of advantages.

\subsection{Isotropic finishing}

Superfinishing is a technique of final machining in a controlled gentle manner to reduce surface finish. The particular technique of superfinishing described in this Paper uses oxalic acid and low density polishing media to preferentially remove surface asperities. The oxalic acid oxidizes the surface which causes the asperities to be more susceptible to "micro honing" with the result that the most positive (peaks) surface areas are removed progressively. The polishing media are selected to span the machining lay and therefore cutting of the negative (valleys) surface areas are avoided.

Consequently the symmetry of the profile can be altered producing a negative skew (Rsk). Ideal for contact conditions where peaks are removed and valleys retained.

This technique becomes particularly efficient when preceded by shot peening: As shown before, the depth of compressive residual stress induced by shot peening is in the range of hundreds microns: any process done to reduce roughness such as polishing or honing might reduce the beneficial effect from shot peening effect. With this Superfinishing technique, the loss of material will be in the range of 10 microns, and there would be a very efficient combination of 


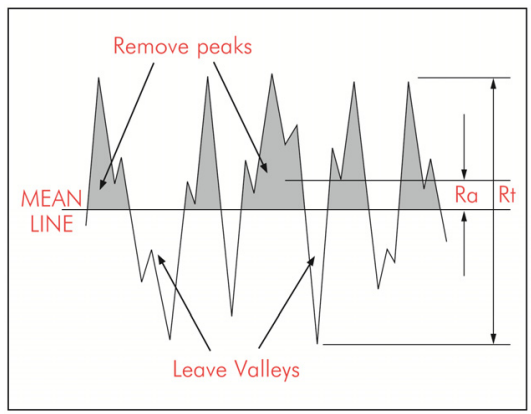

Figure 3: $\quad$ Isotropic finishing process.

compressive residual stress and surface roughness. The technique is not an adaptation of electropolishing where all of the profile of the surface is de-plated with peaks achieving greater attention. The technique of Superfinishing described here has all of the surface oxidized but the honing action initially addresses peaks only which when partially removed, re-oxidizes immediately making them more susceptible to further reduction. As typical roughness profile modification, following Figure 4 [1] could be presented.
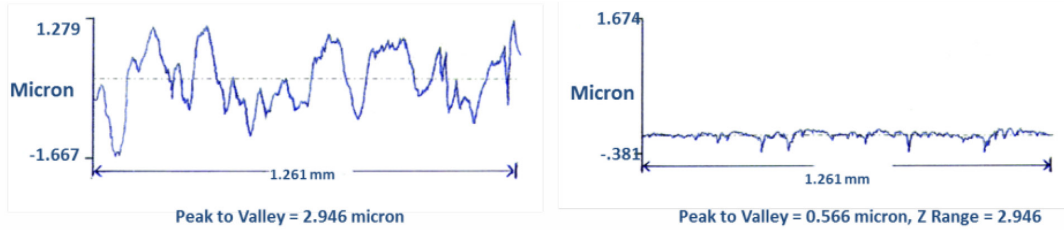

Figure 4: Roughness profile modification from shot peened surface to isotropic finished surface.

The surface roughness after isotropic finishing process present low Ra values and negative Rsk values, giving high performance when metal to metal contact occur. The optimized surface, avoid the contact between peaks, because these have already been removed by the process, assuring an extensive and nondirectional contact. This effect could be seen by analysis made on transmission oil used in a gearbox: as shown in Figure 5 [1], the percentage of iron content in oil used in superfinished gears is almost equal to zero, because the surface asperities that usually could be found have been already removed.

Tests have been completed investigating the oxidizing effect to determine whether preferential grain boundary attack was experienced and whether deposits remained in the surface which could cause problems at a later date. Oxygen mapping was also conducted across a processed area processed to assess concentration or local oxidation problems and none were noted. Element checks were made using SEM equipment on surface peaks and valleys on the same sample, again, no traces were evident in the valley areas. The above is achieved 


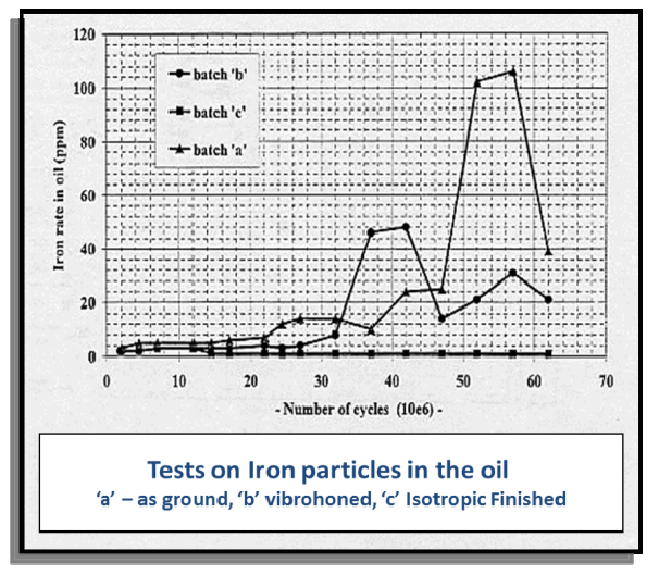

Figure 5: $\quad$ Iron content in the oil.
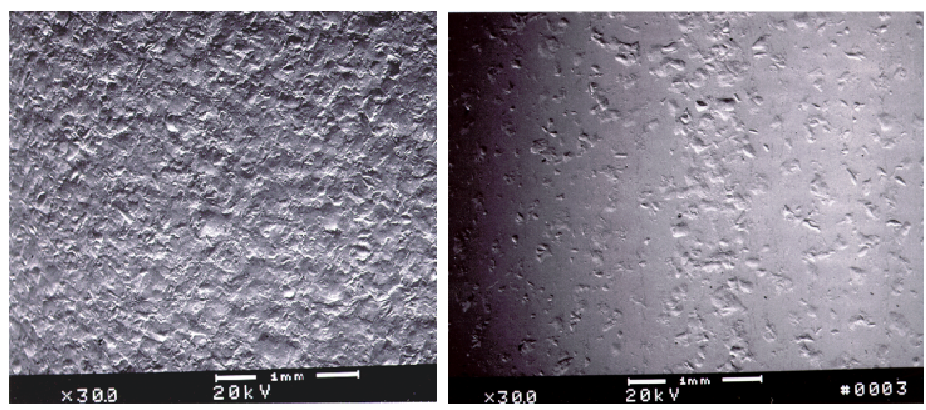

Figure 6: SEM images of surface after shot peening and after isotropic finishing.

because once adequate metal removal has been achieved, neutralizing chemicals are added to prevent further oxidation. Once adequate checks of the technique were conducted, gears were processed to assess practical benefit. It was established that the process could be varied to suit the application.

The final finish is dependent on the starting condition and the time to process. Typical trials [4] on hobbed gear flanks with a starting roughness of 0.6 micron Ra produced data shown in Table 1 . In these examples most of the witness of prior processes has been removed. It is practical to reduce this level of work by decreasing the "micro honing” period. This approach may be necessary where the optimum roughness is unnecessary and only the worst asperities need removal. 
Table 1: $\quad$ Roughness parameters with/without isotropic finishing.

\begin{tabular}{|l|c|c|c|c|}
\hline & \multicolumn{2}{|c|}{ Readings taken Axially } & \multicolumn{2}{c|}{ Readings taken Radially } \\
\hline & Shot peened & $\begin{array}{c}\text { SP }+ \\
\text { superfinished }\end{array}$ & $\begin{array}{c}\text { Shot } \\
\text { peened }\end{array}$ & $\begin{array}{c}\text { SP + } \\
\text { superfinished }\end{array}$ \\
\hline $\mathrm{Ra}$ & $0.494 \mu \mathrm{m}$ & $0.059 \mu \mathrm{m}$ & $0.526 \mu \mathrm{m}$ & $0.054 \mu \mathrm{m}$ \\
\hline $\mathrm{Rt}$ & $2.944 \mu \mathrm{m}$ & $0.446 \mu \mathrm{m}$ & $2.946 \mu \mathrm{m}$ & $0.566 \mu \mathrm{m}$ \\
\hline $\mathrm{Rp}$ & $1.488 \mu \mathrm{m}$ & $0.170 \mu \mathrm{m}$ & $1.279 \mu \mathrm{m}$ & $0.184 \mu \mathrm{m}$ \\
\hline $\mathrm{Rv}$ & $1.456 \mu \mathrm{m}$ & $0.276 \mu \mathrm{m}$ & $1.667 \mu \mathrm{m}$ & $0.381 \mu \mathrm{m}$ \\
\hline Rsk & 0 & -0.5 & -0.2 & -1.1 \\
\hline
\end{tabular}

where:

$\mathrm{Rp}=$ Maximum height of the profile above mean line $\mathrm{Rv}=$ Maximum depth of the profile below mean line Rsk = Measure of symmetry of profile

\section{Main failure mechanism and shot peening/superfinishing effect}

Failure mechanisms of components are complex and to define them adequately would require in depth explanation beyond the scope of this paper, where all aspects of material structure, composition, heat treatment, design and accuracy should be discussed.

When investigating a failure mechanism, an initial analysis of Manufacturing Techniques and their effect on surface roughness and residual stress should be necessary, because the method of manufacture will have a significant effect upon the component performance.

Manufacturing techniques vary the final stress pattern on the surface. In general the thermal manufacturing processes (welding, laser cutting, electric discharge machining, wire cutting) leave the surface with residual tensile stresses of high magnitude and a heat affected re-cast layer. The depth will vary considerably with thermal manufacturing techniques but tensile stresses are normal. Chemical engineering techniques will not impart residual stresses, but will release constrained internal stresses resulting in distortion and can initiate a localised Intergranular attack, which, dependant on the base material and the application may be detrimental.

The mechanical methods of manufacturing such as milling, turning, drilling and grinding vary the end result. The sharpness of the tool and speed of cutting are factors which affect the surface stress pattern. Shot Peening after all of these manufacturing techniques will leave a residual compressive stress of the known magnitude and depth previously. Consequently the influence of these manufacturing stresses are reduced or negated resulting in a reduction in the scatter phenomena that fatigue normally exhibits, and an increase in fatigue strength. 


\subsection{Fatigue and pitting}

Fatigue in metals is the result of repeated or cyclic loads at levels insufficient to cause large amounts of plastic deformation but sufficient to accumulate damage which may cause failure. One characteristic of fatigue is the random or unpredictable nature of its occurrence. This is often the result of variability in the manufacturing process from heat treatment or machining.

Surface finish and residual stress are important aspects where contact fatigue and surface pitting result. The approach taken to resolve both these issues is best viewed separately. Contact fatigue is a 'macro' Hertzian pressure as a result of the geometry of the parts, and can be resolved by ensuring that at the point of maximum pressure is also the point of maximum residual compressive stress induced by heat treatment and/or controlled shot peening.

Surface fatigue/pitting partly develops from 'micro' Hertzian pressures as a result of the surface roughness where asperities cause stress concentration on the mating face. Accentuated further when asperities meet asperities. Micropitting result in a significant proportion of the load being carried by the asperities. During initial operation, localised plastic deformation on the surface asperities introduces modified residual stress patterns and this, combined with the applied cyclic stress, results in fatigue crack initiation. Controlled shot peening induces beneficial compressive residual stress, and isotropic finishing assures the optimal contact between metals, because peaks have already been removed by process. In addition, the influence of the negative (valleys) surface will retain lubricant and/or enable contact relief points reducing pick up or adhesion.

\subsubsection{Fretting}

Fretting occurs when two highly loaded members have a common surface at which rubbing and sliding take place. Relative movements result in surface degradation, oxidation, and often fatigue cracks. Fine abrasive oxides develop that further contribute to degrade the surfaces. Shot peening has been used to prevent fretting and eventual fretting failures by texturing the surface with a nondirectional finish. The surfaces "lock" together and stop the relative movement between the surfaces. The shot peening also increases surface hardening (of certain materials) and induces a layer of compressive stress. The increased surface hardness improves the wear characteristics and the compressive layer prevents initiation and growth of fretting fatigue cracks.

\subsubsection{Stress corrosion cracking}

Tensile related corrosion failures can be derived from either static or cyclic tensile stresses. In both types of failures, environmental influences contribute to failure.

Stress corrosion cracking (SCC) failure is most often associated with static tensile stress. The static stress can be from applied stress (such as a bolted flange) or residual stress from manufacturing processes (such as welding). For SCC to occur three factors must be present: Tensile stress, susceptible material, corrosive environment. 


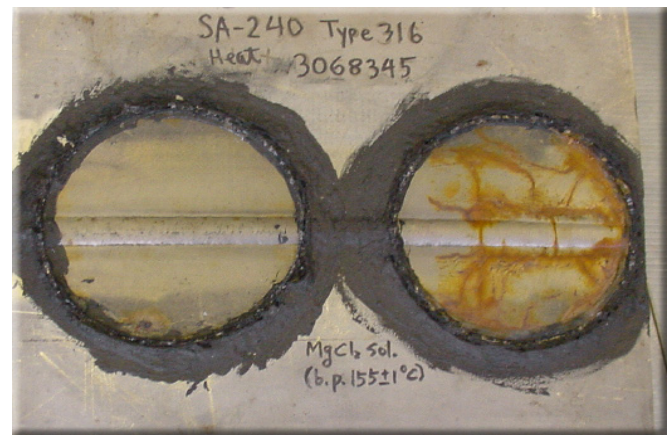

Figure 7: Stress corrosion cracking in peened and unpeened part. SCC is completely absent in peened part.

The compressive layer from shot peening removes the tensile stress component from the SCC “triangle". Without tensile stress, SCC failure is prevented from ever occurring.

\section{Conclusions}

Residual stresses and roughness will vary significantly the performance of a component. Superfinishing of surfaces following the shot peening process, if tailored to suit the application adequately, will result in optimized residual compressive stress and surface texture; in particular, where metal to metal contact occurs, Isotropic Finishing will reduce micro/macro pitting. Controlled shot peening to give a repeatable magnitude and depth of compressive stress, and the correct use of the process parameters for the application, create the right stress profile for fatigue or corrosive benefit. Practical experience in processing parts for various industries has shown significant improvement in contact fatigue and surface pitting. The influence of variations in manufacturing techniques can be reduced or eliminated.

\section{References}

[1] Shot Peening Applications, Ninth Edition, Metal Improvement Co Inc, 2005.

[2] Wohlfahrt, H., Second International Conference on Shot Peening, The American Shot Peening Society, pp. 316-331, 1984.

[3] Austin, K.E., Aylott, C.J. and Shaw, B.A., Understanding gear fatigue performance, Engineering Integrity, 22, pp. 11-19, 2007.

[4] O’Hara, P., Superfinishing of Surfaces to reduce contact Fatigue/Surface Pitting of Transmission Components. Drives \& Controls Conference, Telford 1996. 